\title{
Hybrid manufacturing of sheet metals and functionalizing for joining applications via hole flanging
}

\author{
Markus Bambach $^{1} \cdot$ Ismail Ünsal $^{2}$ (D) $\cdot$ Alexander Sviridov $^{2} \cdot$ Rebar Hama-Saleh $^{3} \cdot$ Andreas Weisheit $^{3}$
}

Received: 6 October 2020 / Accepted: 22 December 2020

(c) The Author(s) 2021, corrected publication 2021

\begin{abstract}
Efficient lightweight solutions are of great interest in many industries (aviation, automotive) particularly regarding the limitation of $\mathrm{CO}_{2}$-emissions and material waste. An innovative strategy to address these challenges is the use of hybrid manufacturing. Additive manufacturing (laser metal deposition, LMD) and conventional forming methods (hole-flanging) are used to optimize and functionalize AA 6016 sheet metal parts, which are widely used in the manufacturing of car body parts. First of all, the effects of the additive reinforcements on the mechanical and microstructural properties are investigated using tensile and microstructural tests. After manufacturing reinforced blanks and performing subsequent forming operations, the parts are investigated regarding damages and functionalized through threading. This allows the application of a bolt connection, which is tested through rip-off tests to evaluate the effect of the reinforcements on the fracture forces. It can be shown, that reinforcements can be manufactured without defects and virtually no porosity and the formability is only slightly reduced compared to conventional materials. At the same time, the performance of the reinforced bolt joint can be enhanced while the increase in weight can be limited to relatively small amounts.
\end{abstract}

Keywords Hybrid manufacturing $\cdot$ Laser metal deposition $\cdot$ Lightweight design $\cdot$ Hole flanging

\section{Introduction}

Ismail Ünsal

uensal@b-tu.de

Markus Bambach

mbambach@ethz.ch

Alexander Sviridov

sviridov@b-tu.de

Rebar Hama-Saleh

rebar.hama-saleh@ilt.fraunhofer.de

Andreas Weisheit

andreas.weisheit@ilt.fraunhofer.de

1 Institute of Virtual Manufacturing, ETH Zrich, Technoparkstrasse 1, 8005 Zurich, Switzerland

2 Chair of Mechanical Design and Manufacturing, Brandenburg University of Technology, Cottbus-Senftenberg, Germany

3 Fraunhofer-Institut fuer Lasertechnik, Steinbachstrasse 15, 52074 Aachen, Germany
Recent developments in national and international (EU) legislation limiting the $\mathrm{CO}_{2}$ output for different industries results in a consistently high demand for innovative light weight solutions.

For sheet metal parts and semi-finished products, tailored blanks and patchwork blanks are a common solutions. Metal parts are reinforced with defined patches of the same or differing material, using spot welding and adhesive methods to combine both [1]. These methods come with several disadvantages, such as high corrosion tendency, weak bonding between the base material and the patch, limited design freedom. A novel approach to tackle these challenges is the creating reinforcements using additive manufacturing (AM) methods. This approach was implemented to produce functional elements [2,3] or local reinforcements [4, 5] using laser beam melting, laser metal deposition or friction stir welding [6]. It makes free design of reinforcement geometries possible as shown in Fig. 1 and leads to a metallurgical bond between the base material and the patch. Also, different material e.g. titanium, aluminum and steel were used and validated. Furthermore, the application of curved 


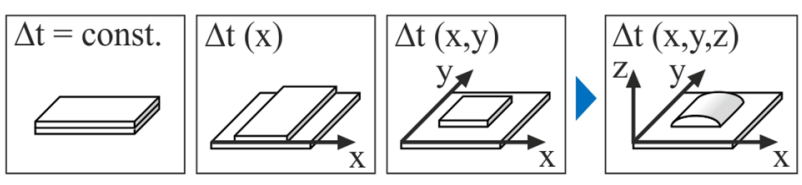

Fig. 1 Extension of patchwork blank techniques with additive manufacturing resulting in 3-dimensional reinforcement geometries

surfaces is possible [7]. In this work, this approach shall be extended to the material AA 6016 using laser metal deposition (LMD). The impact on the hardening properties and the microstructure as well as the mechanical properties shall be investigated. Furthermore, a method to assess the formability of such reinforced blanks and the utilization as a joining possibility should be assessed and quantitatively measured. In special, the counteraction to the induced thinning during the forming process, which can be achieved to the local reinforcement, will be investigated. This will enable the use of this flanges as joining points via bolt joining.

\section{Material and methods}

\subsection{Material}

In this chapter, detailed information regarding the material and methodology is given. The process sequence and the investigations taken at different steps are detailed and explained. This includes performed tests and investigations. The material used in this study is the aluminum alloy AA 6016 with main alloy components magnesium and silicon. In Table 1 detailed information about the chemical composition and the mechanical properties is provided. The mechanical properties correspond to the heat treatment state $\mathrm{T} 4$, which can be achieved through annealing at temperatures around $540{ }^{\circ} \mathrm{C}$ for $10 \mathrm{~min}$ and subsequent quenching in water with subsequent natural aging [8]. The combined annealing and quenching process leads to a solution of the alloy components in the metal lattice in a meta-stable and oversaturated state. A following ageing at $180{ }^{\circ} \mathrm{C}$ for $20-30$ min leads to the state with peak strength, denoted as T6. This increased strength is achieved through precipitation hardening. In this process, the $\mathrm{Mg}$ and $\mathrm{Si}$ atoms migrate and form $\mathrm{Mg}_{2} \mathrm{Si}$ precipitates as the strengthening phase [9]. The material is especially used in the manufacturing of automotive body panels, as the hardening process can be done simultaneously alongside the painting process. The sheet material used in this work consists of cold rolled sheets with a thickness of $1 \mathrm{~mm}$ [10]. The metal powder used for the LMD process was manufactured via a gas atomization process with argon as process gas. The resulting particle diameters were in a range of $45-90 \mu \mathrm{m}$ with a spherical particle geometry. This range is generally chosen for the LMD process, because finer or coarser powder tends to be problematic with respect to transportation (Fig. 2). The main problems are clogging of the transport tubes for coarser powder and agglutination for the finer powder. Furthermore, a bigger powder diameter can lead to pores and inclusions. This can be avoided with a new set of parameters (usually a higher laser power). The amount of $\mathrm{Si}$ was measured using EDx analysis and was in a range of $0.44-1.51 \%$.

\subsection{Process sequence and sample geometry}

In Fig. 3 the complete process analyzed in this study is shown from adding reinforcement to sheet metal to ripoff testing. The aluminum sheets are cut into $80 \times 80 \mathrm{~mm}^{2}$ square blanks and reinforced in the center with a circular patch with $20 \mathrm{~mm}$ diameter using laser metal deposition, which will be explained in detail later.

The sample geometry, which is manufactured using LMD is shown in Fig. 4 The thickness of the reinforcement shown in this example has a thickness between 0.3 and $0.4 \mathrm{~mm}$

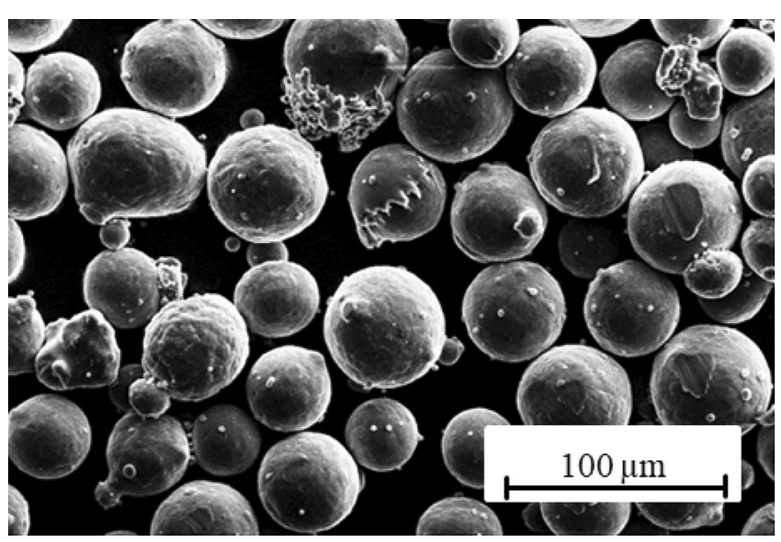

Fig. 2 Micrograph of aluminum powder with spherical particles
Table 1 Mechanical and chemical properties of AA 6016

\begin{tabular}{|c|c|c|c|c|c|c|}
\hline \multirow[t]{3}{*}{ Material } & \multicolumn{3}{|c|}{ Material properties } & \multicolumn{3}{|c|}{ Alloy composition } \\
\hline & YS & UTS & $A_{80}$ & $\mathrm{Mn}$ & $\mathrm{Mg}$ & $\mathrm{Si}$ \\
\hline & $\mathrm{MPa}$ & & $\%$ & & $\mathrm{wt} \%$ & \\
\hline AA 6016 & 120 & $>250$ & 24 & 0.2 & 0.2 & 0.2 \\
\hline
\end{tabular}




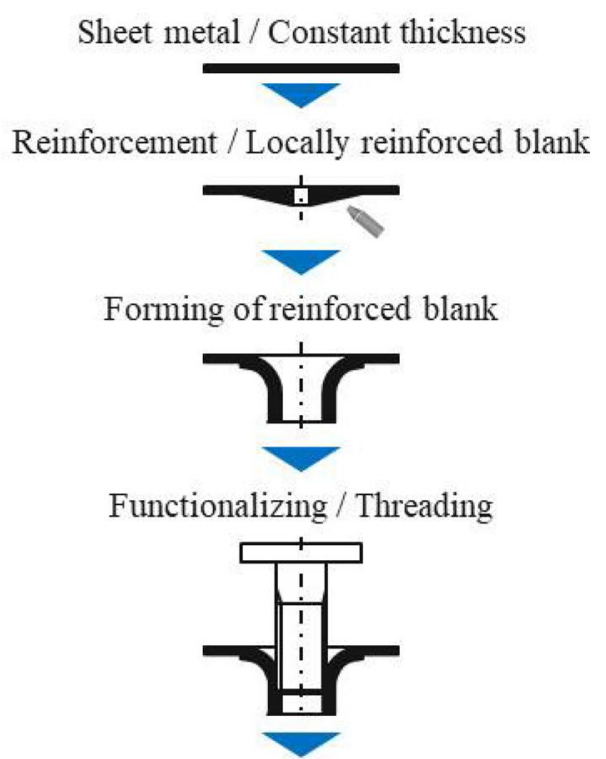

Heat treatment

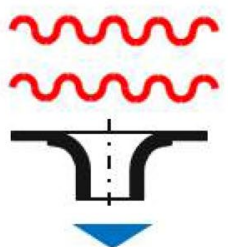

Testing / Rip-off test

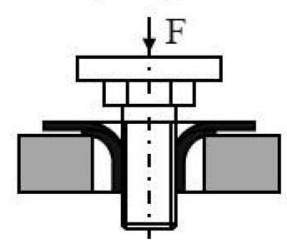

Fig. 3 Process sequence for the reinforcement and functionalizing of a sheet metal part using laser metal deposition

which corresponds to single layer of adjacent weld beads. Thicker reinforcements can be manufactured by welding more layers on top of each other. Furthermore, a circle with 6 holes and a diameter of $6 \mathrm{~mm}$ is added for the later fixation in the forming process. Samples are then drilled in the center to achieve different hole diameters for the following hole flanging operation, which leads to different hole expansion ratios (HER). The hole expansion ratio is defined as the ratio between the diameter of the formed flange and the diameter of the hole prior to the flanging process. The prepared samples are hole-flanged and analyzed regarding the final part geometry. Before functionalizing, some samples will be heat treated to compare the forces at failure for parts directly after reinforcing and after reinforcing and hardening. Through threading, the parts can be utilized as a bolt joint and tested via rip-off tests. The microstructure investigations (hardness, porosity, crack emergence) were performed after

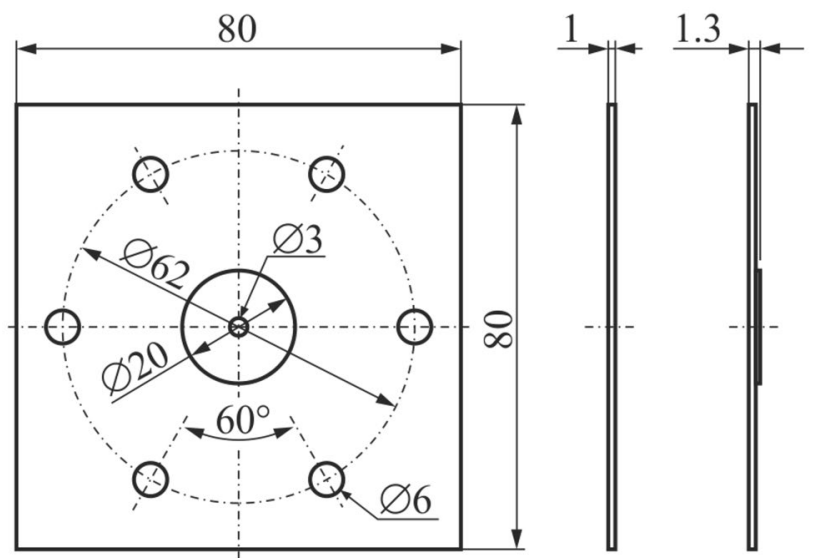

Fig. 4 Sample geometry for additively reinforced blanks

reinforcing the blanks and after heat treatment to the T6 state of reinforced blanks. This enables an assessment of the hardenability of the deposited AA 6016 material and if this property is altered during the LMD-process. Furthermore, after the forming was performed, another micro-analysis of the formed material was performed to compare the tendency of developing damage in the deposited reinforcement layer.

\subsection{Manufacturing of reinforcements and testing}

In Fig. 5a the LMD process is illustrated. In this additive manufacturing process, the filler material (powder) is melted using laser radiation. To achieve this, the powder is coaxially fed into the interaction zone with the laser radiation. The laser melts the surface of the substrate material and forms a melting pool into which the powder is blown $[11,12]$. The reinforcement is manufactured using a trajectory that corresponds to an Archimedean spiral with an offset between welding beads of $0.5 \mathrm{~mm}$. Since the widths of the beads are around $1 \mathrm{~mm}$, a good overlapping can be achieved.

An image from the real process image during the manufacturing of the described circular reinforcements is shown in Fig. 4b. The laser used in this study is a $2 \mathrm{KW}$ diode laser. The used parameters are shown in Table 2.

To determine the influence of the additive manufacturing process on the mechanical properties of the reinforced blank, tensile test specimen were produced. These specimens were manufactured according to the German industry standard DIN 50125. Rectangular patches with the size of $200 \times 25$ mm were manufactured on a blank, as shown in Fig. 4a. The dimensions of this patch were chosen larger compared to the final specimens with a margin of $10-15 \mathrm{~mm}$ to ensure that the peripheral zone of the patch can be cut of, as the properties in this area may vary compared to the rest of the patch. This variation is caused by the dynamic motion of the laser nozzle and the robot and the switching on/off off the laser. 
a

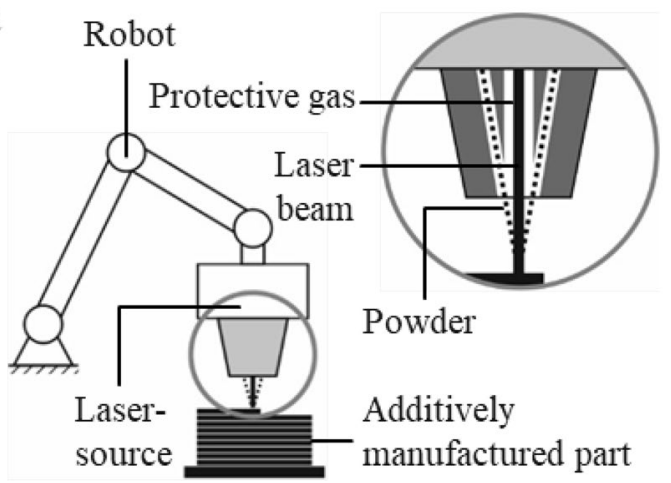

b

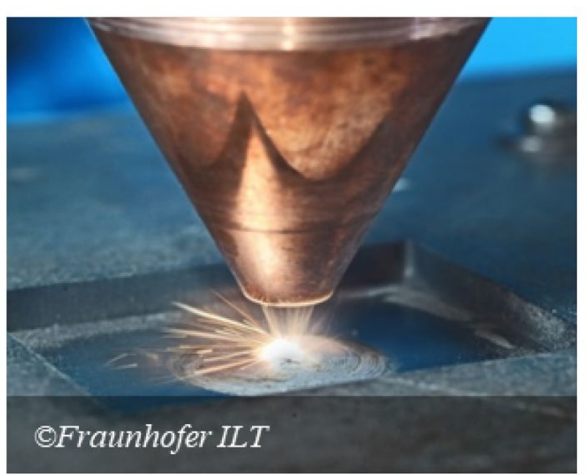

Fig. 5 a Illustration of the laser metal deposition process and $\mathbf{b}$ real process image

Table 2 Mechanical and chemical properties of AA 6016

\begin{tabular}{ll}
\hline Parameter & Value \\
\hline Scanning speed (mm/min) & 2500 \\
Power (W) & 800 \\
Powder mass flow (g/min) & 2.3 \\
Thickness of single layer (mm) & $0.3-0.4$ \\
\hline
\end{tabular}

The tensile test specimens were then manufactured using milling. With this sample design, the tensile test properties of reinforced blanks were determined using a ZWICK Z250 universal testing machine (Fig. 6).

\subsection{Microstructure and hardness}

To gain insight into the microstructure of the patchwork blanks, the samples are investigated using light optical microscopy (LOM). The main aim is to detect cracks or pores in the reinforced section and microstructural changes to the base and added material. The samples were cut and embedded using synthetic resin enabling the investigation of the cross section. In a following step, the samples were ground and polished with abrasive paper of different grain size levels $(1200 \mu \mathrm{m}$ to $0.05 \mu \mathrm{m})$ and investigated

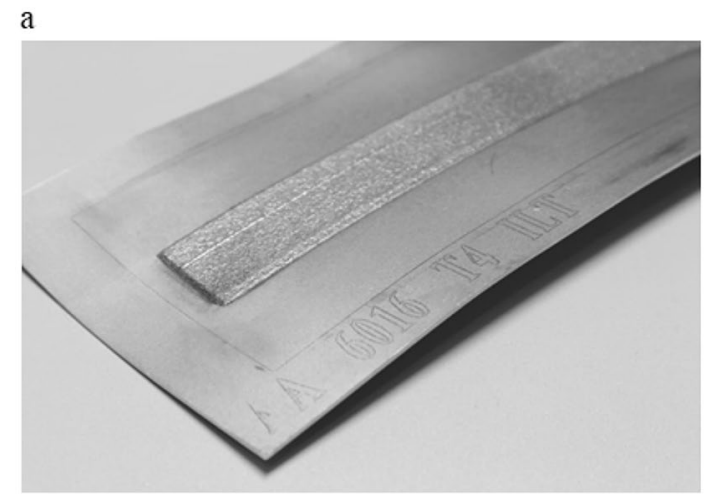

b

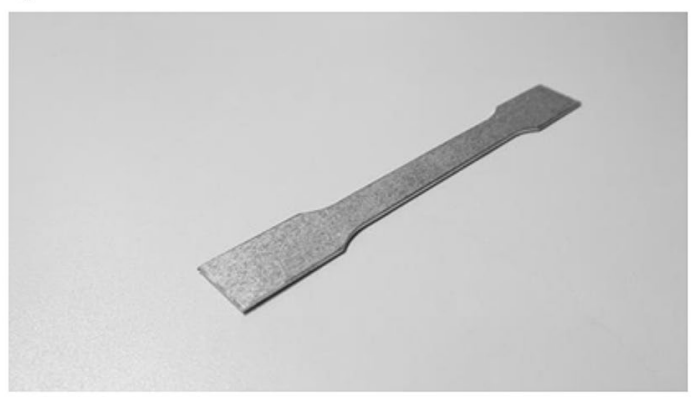

Fig. 6 a Additive reinforced blank and $\mathbf{b}$ manufactured tensile test sample

using LOM. Furthermore, the hardness values throughout the cross-section were determined using Vickers hardness tests with a testing force of $0.3 \mathrm{kp}$. The hardness was tested directly after the reinforcement process, which can also be regarded as first heat treatment. Additional hardness tests wer performed with the same setup after the precipitation hardening of the reinforced part.

\subsection{Hole flanging experiments}

The prepared and pre-drilled samples were hole flanged using a conventional process set-up with a hemispherical punch shape with $10 \mathrm{~mm}$ diameter as shown in Fig. 7. The sample was oriented in such a way that the punch always contacted the sample from the non-reinforced surface. This approach was chosen to prevent excessive wear to the punch resulting from the rough surface of the reinforced area and to enable the following threading on the inner surface of the flange. The forming process was conducted with a downward movement of the punch with constant speed of $4000 \mathrm{~mm} /$ min. For lubrication, the standard lubrication oil CLF W-100 of the manufacturer Raziol was used.

The die cavity had a diameter of $12.5 \mathrm{~mm}$, which leads to a forming gap of $1.25 \mathrm{~mm}$. As the thickness of the reinforced blanks range from 1.4 to $2.2 \mathrm{~mm}$ for a different number of reinforcement layers (with a layer thickness of 0.3-0.4 for a single layer), the material was stretch-flanged in the forming 


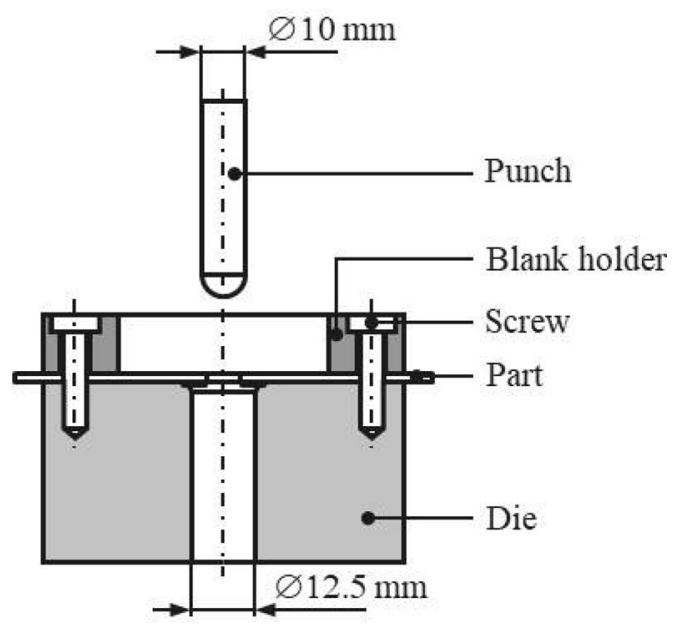

Fig. 7 Illustration of the hole flanging operation with reinforced specimens

gap, which affected the part geometry. In Fig. 8 a locally reinforced sample is. The heat impact on the specimen during the additive layering led to a slight bulging. The overall warping of the sample is negligible concerning the effect on the following forming operations.

\subsection{Functionalizing and testing}

The reinforced and formed specimens were then functionalized through threading. The threading was performed with a
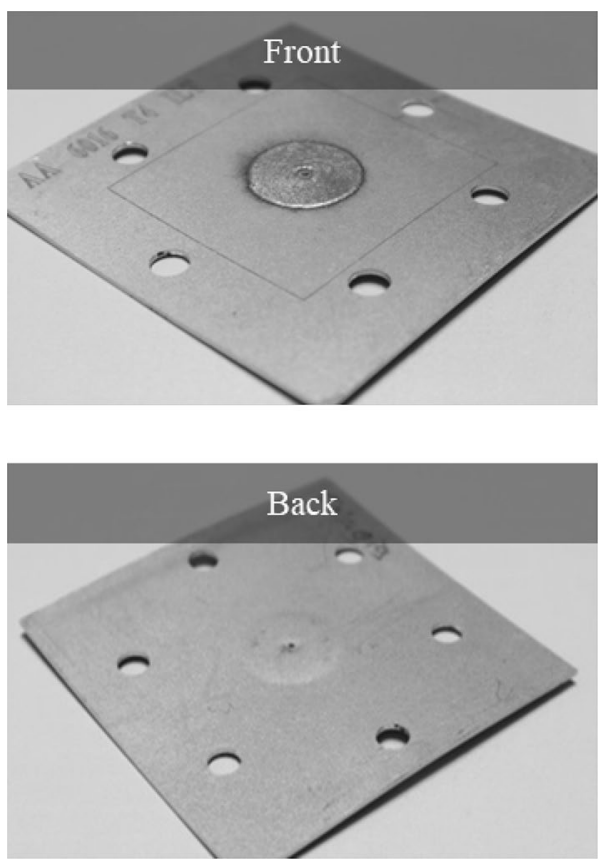

Fig. 8 Locally reinforced sample for hole flanging
7/16 UNF screw tap, matching the flange hole with $10 \mathrm{~mm}$ diameter and wall thicknesses between 1 and $1.5 \mathrm{~mm}$. The samples were then tested by applying a downward force with $20 \mathrm{~mm} / \mathrm{min}$ punch speed on a bolt as shown in Fig. 9. The die cavity for this test is increased to $15 \mathrm{~mm}$ to prevent contact between the flange and the die while still supporting the part directly on the reinforced area. This ensured that solely the function of the reinforced area was tested.

\section{Results}

In this chapter, the results of the different steps in the process sequence will be presented. First, the mechanical properties of the reinforced blanks will be shown and the influence on the relevant properties described. Following, the geometry of the reinforced blanks such as the microstructural changes (cracks, hardness, and porosity) will be detailed. Finally, the results of the hole flanging process of the reinforced blanks and the rip-off tests are given.

\subsection{Mechanical properties and microstructure}

\subsubsection{Mechanical properties}

The mechanical properties of the conventional blank material and the reinforced samples are visualized in the

a

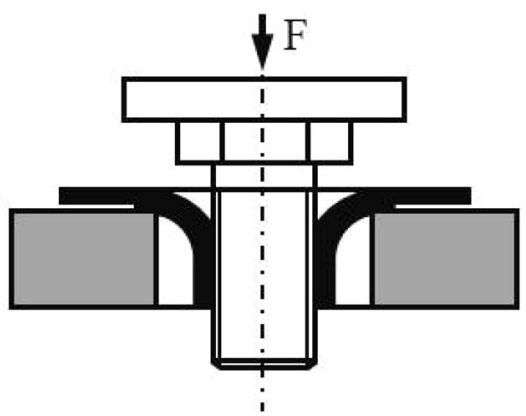

$\mathrm{b}$

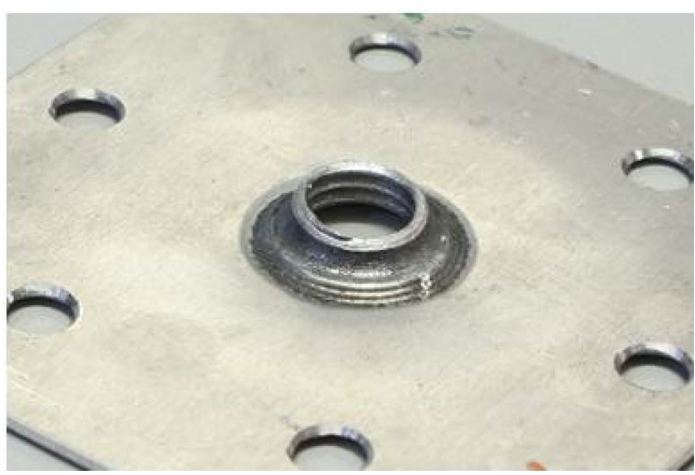

Fig. 9 a Schematic set up for rip-off tests and $\mathbf{b}$ threaded part 
stress-strain diagram in Fig. 10. The first important observation is, that the material behavior with respect to the yieldstrength is hardly affected by the LMD process, i.e. this property remains roughly the same for the conventional and the reinforced material. This result was obtained directly after the manufacturing of the reinforcement. Furthermore, the average roughness value for reinforced and conventional sheets were measured. The average roughness value for reinforced parts were in a range from 7.1 to $18.3 \mu \mathrm{m}$ compared to conventional material with values in a range from 2.2 to $2.7 \mu \mathrm{m}$. Although the roughness is higher compared to conventional material, it can be assumed that for some industrial applications a following machining and/or polishing is not needed.

The material behavior in the plastic region allows for two observations.

- The elongation at break is reduced by around $50 \%$ for all the reinforcement specimens.

- The tensile strength is reduced the range of 210-230 $\mathrm{MPa}$, while the double layered reinforcement outperforms the single layered one, which is an indication of the rather random heating and cooling behavior in the reinforcement processing.

In Fig. 11, the state after reinforcement and subsequent heat treatment is shown and compared with the T4 and T6 states of the conventional, not reinforced material. A similar behavior compared to the case where the properties were measured directly after the reinforcement process can be observed. However, the decrease in strength is more significant, while the decrease in achievable elongation is

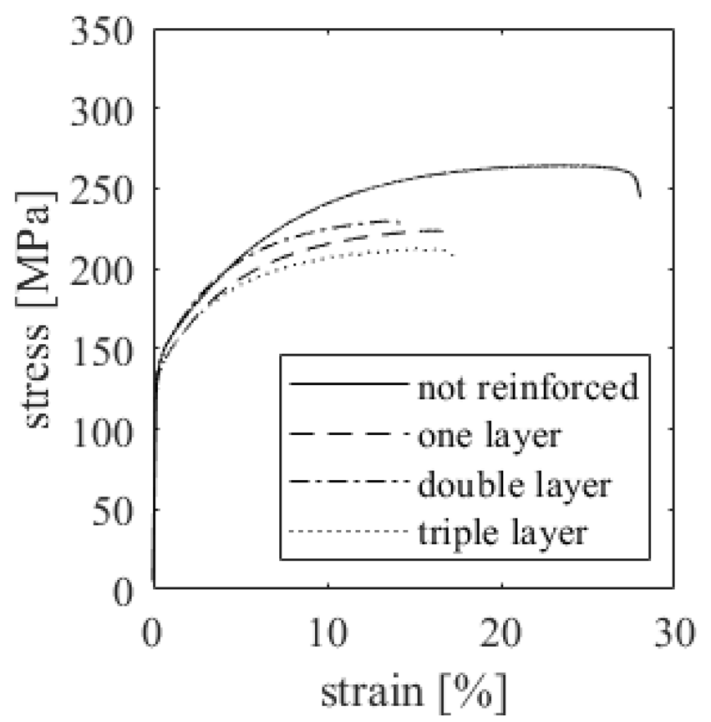

Fig. 10 Stress-strain-curves for reinforced EN AW 6016 T4 sheet metals directly after reinforcement only around 5\%. While Figs. 10 and 11 show representative curves, Table 3 shows the detailed results.

In conclusion, it can be stated that a significant change in the properties are evident, but it can be assumed, that they remain in a relatively small range and are thus controllable. Furthermore, the difference between the different reinforcement grades is almost negligible. These two assumptions are based on the consistent high quality of the deposited material.

\subsubsection{Microstructure}

Micrographs showing the structure of the base material and the reinforcement layer are shown in Fig. 12.

The reinforcement layer contains no visible pores and no major changes in the microstructure can be observed. Very fine cracks with a length of approximately 100-200 $\mu \mathrm{m}$ can be observed in the additive layer. Especially in the edge regions of the additive layer a distinct crack evolution can be observed. The hardness progression for the specimen directly after reinforcement and after subsequent heat treatment is shown in Fig. 13 with the positions shown on one of the samples.

The course of hardness is shown from the bottom edge of the base layer (denoted with 0 ) to the upper edge of the additive layer (denoted with 8 ) whereby every step corresponds to a lateral step of 125 microns. A decrease of hardness in the additive layer of about 25-30 HV0.3 can be observed with random deviations throughout the map. It is noteworthy, that the heat treatment does not result in higher hardness values in the deposited material in contrast to the conventional material.

\subsection{Forming forces}

The impact of the local reinforcement on the forming forces is shown in Fig. 14. Hereby, the ratio of applied force to the blank thickness after reinforcement is illustrated.

The forces are increased quasi-linear with an increasing number of reinforcement layers.

\subsection{Forming limits of reinforced blanks}

As described in Sect. 3.3, the HER can be used as a measure of the achievable degree of deformation and used to compare different set-ups. As shown in Fig. 15, the achievable HER stays mostly identical for the specimens with different numbers of layers added to the substrate blank. Only for the three-layer reinforcement, a slight decrease in the HER could be detected.

In Fig. 16 a successfully formed reinforced flange and a micrograph of the formed area are shown. The layering and metallurgical bond are observable. During the forming, no 
Table 3 Detailed mechanical properties for reinforced and conventional EN AW 6016 sheet metals in different heat treatment states

\begin{tabular}{|c|c|}
\hline YS (MPa) & UTS (MPa) \\
\hline \multicolumn{2}{|l|}{ Not reinf. T4 } \\
\hline 142 & 258 \\
\hline 127 & 264 \\
\hline 134 & 264 \\
\hline \multicolumn{2}{|l|}{ Not reinf. T6 } \\
\hline 247 & 295 \\
\hline 242 & 294 \\
\hline 242 & 294 \\
\hline \multicolumn{2}{|l|}{ Reinf. on T4 } \\
\hline 132 & 215 \\
\hline 130 & 212 \\
\hline 130 & 207 \\
\hline \multicolumn{2}{|l|}{ Reinf. on T4 + T6 } \\
\hline 228 & 265 \\
\hline 213 & 250 \\
\hline 213 & 249 \\
\hline Uniform elong. (\%) & $\begin{array}{l}\text { Fracture } \\
\text { elong. }(\%)\end{array}$ \\
\hline \multicolumn{2}{|l|}{ Not reinf. T4 } \\
\hline 23.7 & 27.1 \\
\hline 23.2 & 27.3 \\
\hline 23.4 & 26.4 \\
\hline \multicolumn{2}{|l|}{ Not reinf. T6 } \\
\hline 16 & 20.5 \\
\hline 12.3 & 16 \\
\hline 13.2 & 15.6 \\
\hline \multicolumn{2}{|l|}{ Reinf. on T4 } \\
\hline 196 & 260 \\
\hline 20 & 21.5 \\
\hline 16 & 22 \\
\hline \multicolumn{2}{|l|}{ Reinf. on T4 + T6 } \\
\hline 8.4 & 12.2 \\
\hline 8.1 & 12.2 \\
\hline 8.3 & 12.7 \\
\hline
\end{tabular}

detachments occurred and no crack propagation can be seen after the forming.

\subsection{Part geometry}

As a result of the additional material, the geometry of the formed part changes with the thickness of the reinforcement. This change can be quantified observing the resulting wall thicknesses and resulting heights of the flanges, visualized in Figs. 17 and 18.
It can be observed, that for both geometrical parameters there is a linear growth. This results primarily from the fact that the additional material is stretch-flanged in the forming gap, which leads to a more robust part geometry. The impact on the functionality will be shown in the next section.

\subsection{Rip off tests of reinforced flanges}

In this section, the effect of the reinforcements on the rip-off tests as described in Sect. 2.6 will be presented. In Fig. 19, the effect of the reinforcement and the heat treatment is 


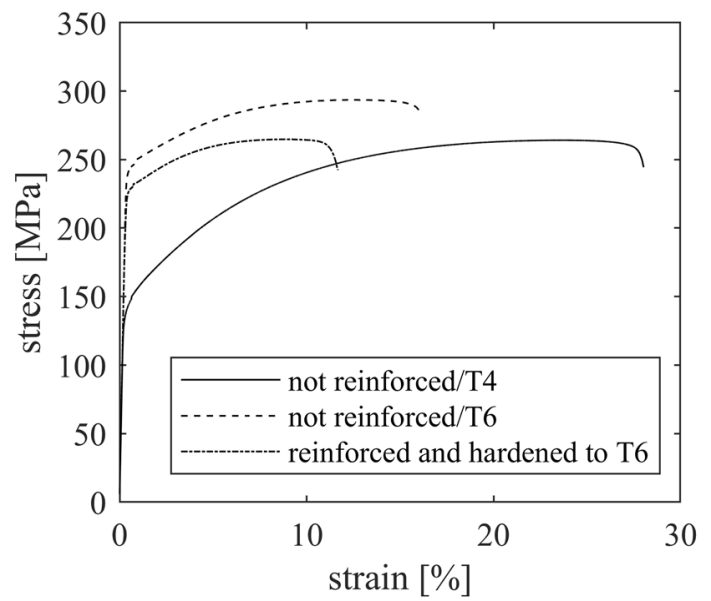

Fig. 11 Stress-strain-curves for reinforced EN AW 6016 T4 sheet metals after reinforcement and subsequent heat treatment to the T6 state

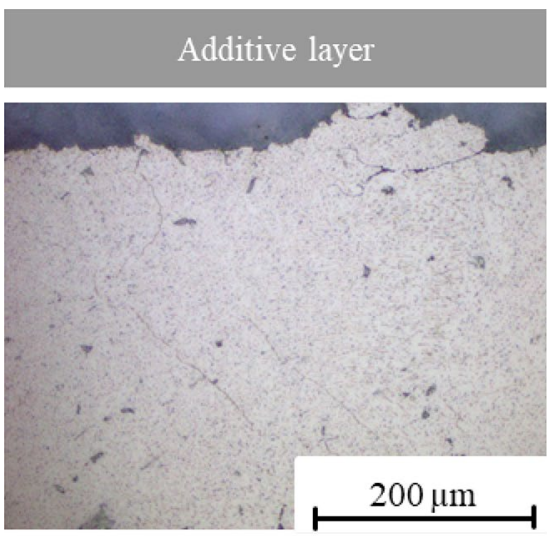

\section{Base material}

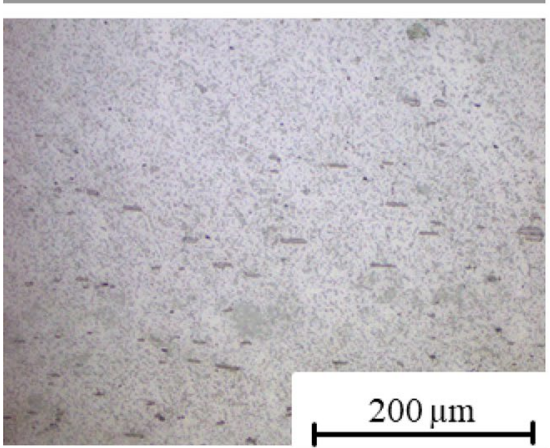

Fig. 12 Micrographs of the additive and base layer of reinforced blank specimens

shown as a ratio of rip-off force and blank thickness. The reinforcement allows for up to $1890 \mathrm{~N} / \mathrm{mm}$ compared to $1500 \mathrm{~N} / \mathrm{mm}$ for non-reinforced blanks. However, if the precipitation heat treatment is considered, the possible force
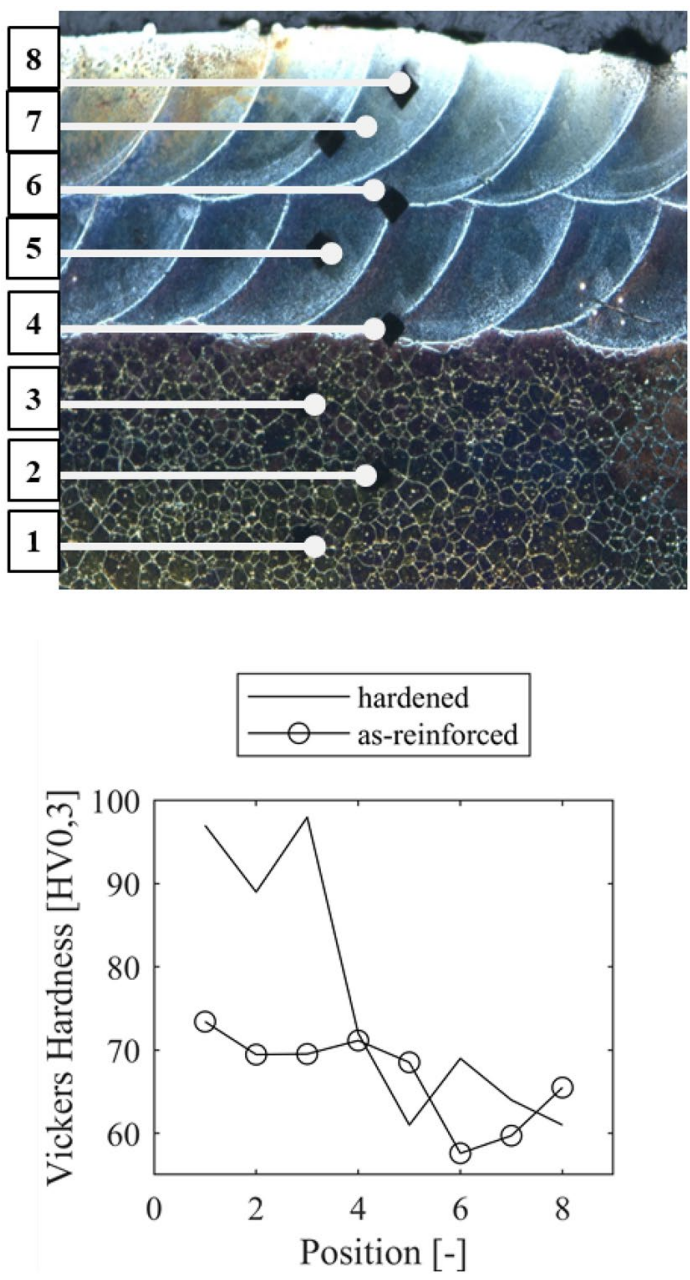

Fig. 13 Hardness progression of reinforced T4 blanks directly after reinforcement and after subsequent heat treatment with 0 denoting the bottom edge of the base layer and 8 denoting the upper edge of the additive layer

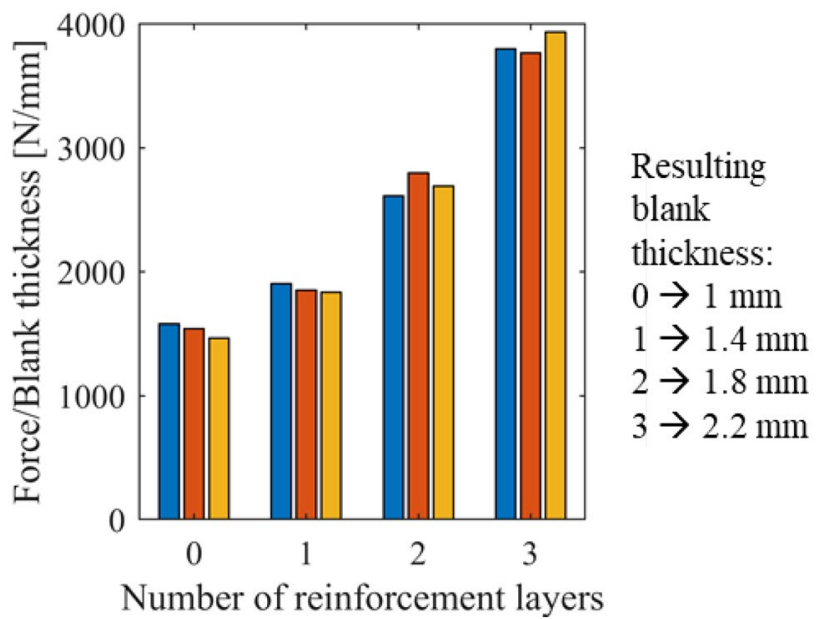

Fig. 14 Comparison of forming forces with regard blank thickness resulting from different numbers of reinforcement layers 


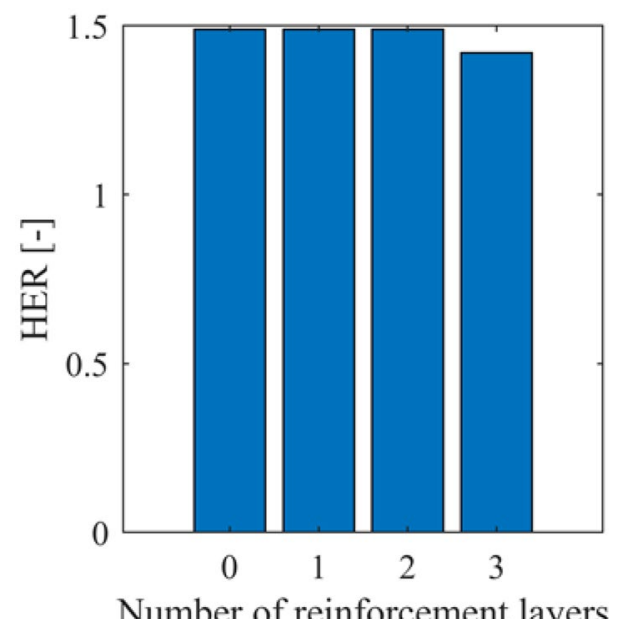

Fig. 15 Comparison of the hole expansion ratios for a different number of reinforcement layers

a

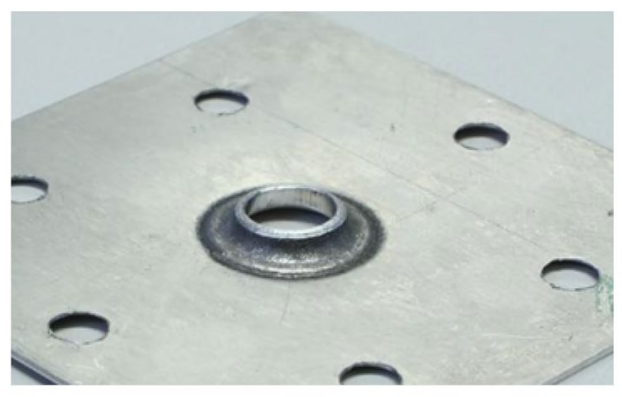

$\mathrm{b}$

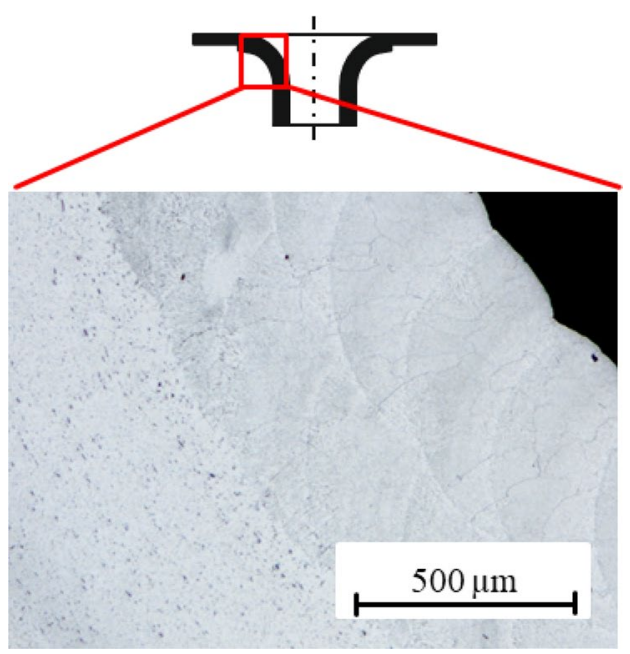

Fig. 16 a Successfully formed reinforced part and b micrograph of cross section of the formed area showing the interface between the additive layers and the interface between the additive and conventional material

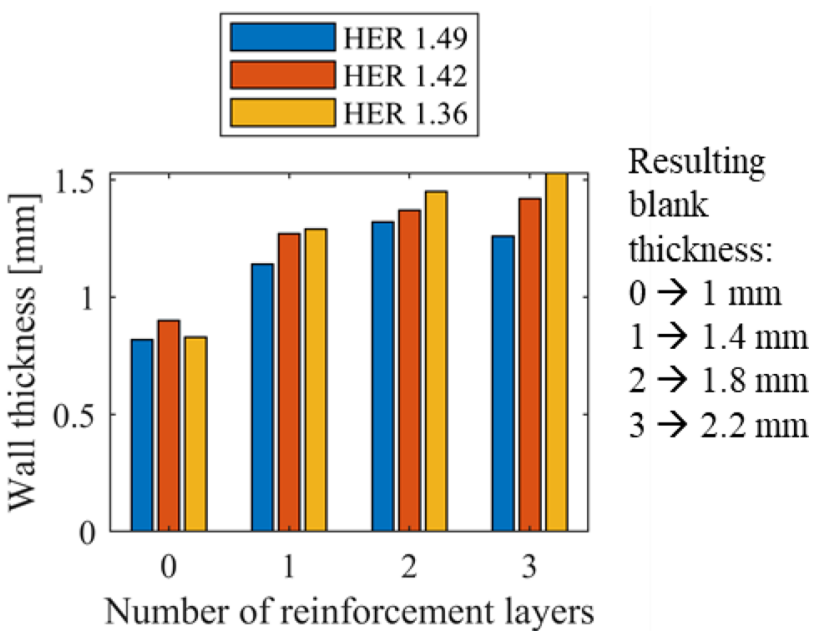

Fig. 17 Influence of the reinforcement thickness on the wall thicknesses for different HER
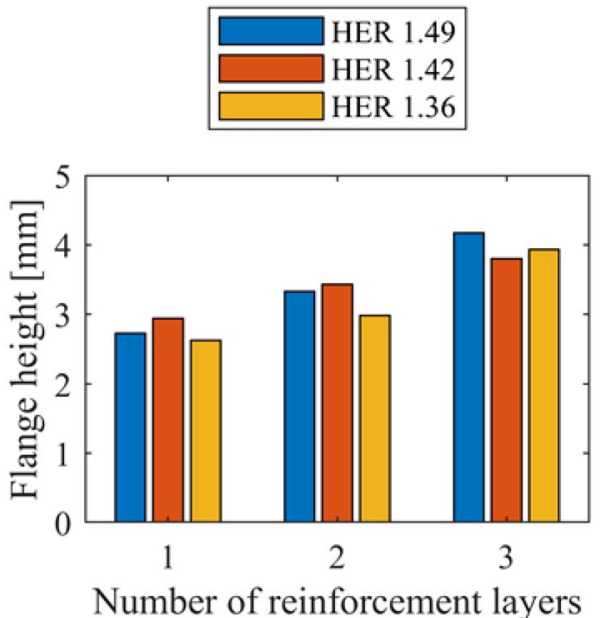

Resulting

blank

thickness:

$0 \rightarrow 1 \mathrm{~mm}$

$1 \rightarrow 1.4 \mathrm{~mm}$

$2 \rightarrow 1.8 \mathrm{~mm}$

$3 \rightarrow 2.2 \mathrm{~mm}$

Fig. 18 Influence of the reinforcement thickness on the flange heights for different HER

reach up to $2690 \mathrm{~N} / \mathrm{mm}$. It is important to note, that the reinforcement can be done in the assembly procedure of e.g. an automobile part, while the hardening is done simultaneously with the painting process.

\section{Discussion}

\subsection{Tensile test properties}

An important aim of this work was to identify forming limits of additively reinforced parts for hole flanging operations with the material AA 6016. The first parameter to evaluate these forming limits was the elongation. Although there was a significant decrease in elongation 


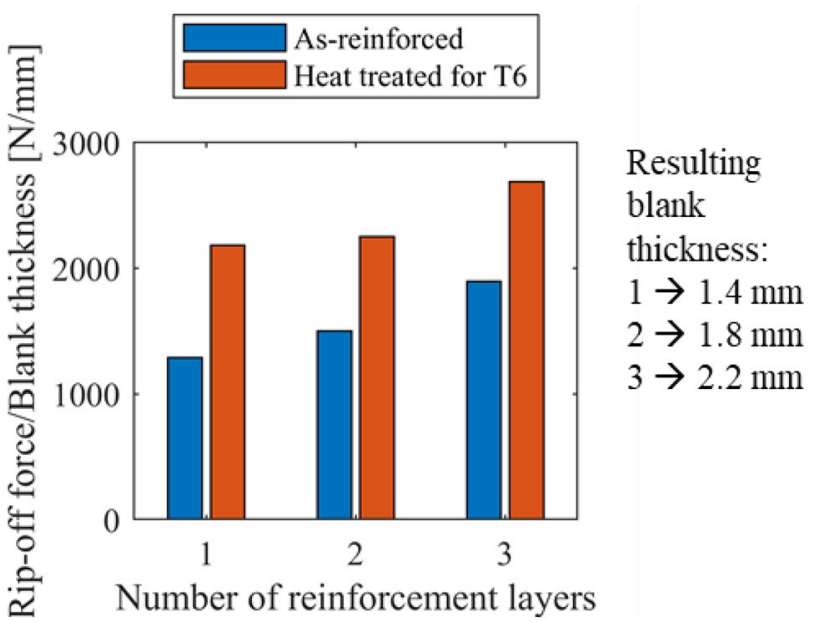

Fig. 19 Influence of the reinforcement and the heat treatment on the bearing capacity of the flanges with $1500 \mathrm{~N}$ for non-reinforced blanks

after the application of the reinforcement was found, the elongation was consistently above $15 \%$ which is an indication for sufficient formability. Furthermore, the sound metallurgical bonding among the reinforcement layers and among the reinforcement layers and the base material supports the findings of the mechanical tests. Finally, by comparing the HERs of different reinforcement thicknesses, it could be shown, that the formability can be conserved even for thick reinforcements.

\subsection{Microstructure and hardness}

The LOM results showed no detectable porosity in the layers, which is unusual for aluminum alloy, which tend to show severe crack and pore formation during welding processes. However, instead of pores, short cracks were detected at the outer edges of the reinforced layers. These can be eliminated using a smoothing step after the reinforcement, e.g. laser polishing. These minor cracks may be the main cause for the finding that the tensile elongation decreased by roughly $5 \%$ compared to the base material. Nevertheless, for some applications, the tensile properties of the reinforced AA6016 may still be sufficient.

The difference after heat treatment to T6 between the base and the reinforcement layer may be caused because some alloy elements are burned off during the welding process. Another possibility is the uneven distribution of the alloy components in the reinforcement layer. Further research is necessary to assess this problem, however, a different composition of alloy elements may change this
Table 4 Comparison of mass and force gain through additive reinforcement directly after reinforcement and with subsequent hardening

\begin{tabular}{llll}
\hline Number of layers & 1 & 2 & 3 \\
\hline Additional mass & $1.4 \%$ & $2.88 \%$ & $4.32 \%$ \\
Force after reinf. & $14 \%$ & $71 \%$ & $164 \%$ \\
Force after subs. hardening & $196 \%$ & $260 \%$ & $380 \%$ \\
\hline
\end{tabular}

behavior. In terms of formability, the reduced hardness of the additive layer could be beneficial for the stretchflanging occuring during hole flanging.

\subsection{Functionalizing and testing}

It was possible to functionalize the flange by adding mass to an otherwise thin blank material. This changed the final geometry of the formed flange. Furthermore, the thinning in the forming process could be compensated, which led to significant improvements in the rip off tests. The additional material made the bolt connection much stronger, because a much more efficient threading could be performed. An almost three-fold increase for the bearable forces before fracture could be achieved. An additional heat treatment made forces up to $6000 \mathrm{~N}$ possible, although the reinforced material did not reach the properties of the base material in the T6 state. To illustrate the performance enhancement from a lightweight standpoint, the increase in weight and applicable forces can be compared.

As shown in Table 4 the increase in the applicable force to the bolt joint is considerably higher then the relatively small change in the parts mass. It is worth noting that the change in mass was calculated for the benchmark part defined in Sect. 2.2. If the reinforcements are applied in larger parts, the lightweight potential can be considerably higher due to the fact that the changes in mass will be insignificant on the part level, while the increase in bearable force may be substantial.

\section{Conclusion}

In this paper, the feasibility of tailored reinforcements manufactured by laser metal deposition on metal material AA 6016 was investigated. The following statements can be made:

- The material can be used for additive reinforcements via LMD. Additive layers with no detectable porosity, no bonding defects but slight short cracks near the surface can be achieved. Hereby, a single layer can be manufactured in roughly $20 \mathrm{~s}$. 
- The reinforced blanks can be hole-flanged with no alterations of the tooling equipment. The forming limits in terms of HER are comparable to conventional material. However, the hardenability of the reinforced material is not given in the same extend as for the base material.

- The mechanical properties change through the reinforcement process but stays in controllable margins. A drop in tensile elongation of about 5\% in the T6 state was observed in the reinforced sheets compared to the base material sheets.

- The reinforcement enables functionalizing of formed parts to achieve optimal lightweight performance.

Further research should concentrate on post-treatment of the welded patches to achieve better tensile properties. Another aspect is the application of the reinforcements to different functions such as improvement of noise and vibration behavior of sheet metal components as well as the service-life duration, which might be changed through the applied reinforcement and thus reduced fatigue strength.

Acknowledgements The depicted results were achieved to a great extent in the project Materialeffiziente Herstellung belastungs- angepasster Blechbauteile mit durch Laseradditiv aufgebrachten flexiblen Verstrkungszonen (Ref.-No. AiF 19292BG), which is financed and supervised by the European Research Association for Sheet Metal Working (EFB). In the scope of the programme to promote Industrial Collective Research they were funded by the German Federation of Industrial Research Associations (AiF) with means of the Federal Ministry of Economic Affairs and Energy (BMWi) on the basis of a decision by the German Bundestag. This funding is gratefully acknowledged.

Funding Open Access funding enabled and organized by Projekt DEAL.

Open Access This article is licensed under a Creative Commons Attribution 4.0 International License, which permits use, sharing, adaptation, distribution and reproduction in any medium or format, as long as you give appropriate credit to the original author(s) and the source, provide a link to the Creative Commons licence, and indicate if changes were made. The images or other third party material in this article are included in the article's Creative Commons licence, unless indicated otherwise in a credit line to the material. If material is not included in the article's Creative Commons licence and your intended use is not permitted by statutory regulation or exceeds the permitted use, you will need to obtain permission directly from the copyright holder. To view a copy of this licence, visit http://creativecommons.org/licenses/by/4.0/.

\section{References}

1. Merklein M, Maren J, Lechner M et al (2014) A review on tailored blanks - production, applications and evaluation. J Mater Process Technol 214:151-164. https://doi.org/10.1016/j.jmatp rotec.2013.08.015

2. Schaub A, Ahuja B, Buthammer L et al (2016) Additive manufacutring of functional elements on sheet metal. Phys Proc 83:797807. https://doi.org/10.1016/j.phpro.2016.08.082

3. Schaub A, Juechter V, Singer RF et al (2014) Characterization of hybrid components consisting of SEBM additive structures and sheet metal of alloy Ti-6Al-4V. Key Eng Mater 611-612:609-614. https://doi.org/10.4028/www.scientific.net/kem.611-612.609

4. Tebaay LM, Hahn M, Tekkaya AE (2020) Distortion and dilution behavior for laser metal deposition onto thin sheet metals. Int J Precis Eng Manuf Green Technol 7:625-634. https://doi. org/10.1007/s40684-020-00203-9

5. Bambach M, Sviridov A, Weisheit A et al (2017) Case studies on local reinforcement of sheet metal components by laser additive manufacturing. Metals 7(4):113. https://doi.org/10.3390/met70 40113

6. Mondal M, Das H, Hong ST et al (2019) Local enhancement of the material properties of Aluminium sheets by a combination of additive manufacturing and friction stir processing. CIRP Ann 68(1):289-292. https://doi.org/10.1016/j.cirp.2019.04.109

7. Ambrogio G, Gagliardi F, Muzzupappa M et al (2019) Additiveincremental forming hybrid manufacturing technique to improve customised part performance. J Manuf Process 37:386-391. https ://doi.org/10.1016/j.jmapro.2018.12.008

8. Engler O, Schfer C, Runar Mhyr O (2015) Effect on natural ageing and pre-straining on strength and anisotropy in aluminum alloy AA 6016. Mater Sci Eng A 639:65-74. https://doi.org/10.1016/j. msea.2015.04.097

9. Wang Y, Zou Y, Shuai H et al (2017) Investigation on fatigue performance of cold expansion holes of 6016-T6 aluminium alloy. Int J Fatigue 95:216-228. https://doi.org/10.1016/j.ijfat igue.2016.10.030

10. Xie Q, Van Bael A, An YG et al (2018) Effects of the isotropic and anisotropic hardening within each grain on the evolution of the flow stress, the R-value and the deformation texture of tensile tests for AA6016 sheets. Mater Sci Eng A 721:154-164. https:// doi.org/10.1016/j.msea.2018.02.053

11. Hama-Saleh R, Weisheit A, Schleifenbaum JH, Ünsal I et al (2020) Formability analysis of micro-alloyed sheet metals reinforced by additive manufacturing. Proc Manuf 47:1023-1028. https://doi.org/10.1016/j.promfg.2020.04.317

12. Kaierle S, Barroi A, Noelke $C$ et al (2012) Review on laser deposition welding: from micro to macro. Phys Proc 39:336-45. https:// doi.org/10.1016/j.phpro.2012.10.046

Publisher's Note Springer Nature remains neutral with regard to jurisdictional claims in published maps and institutional affiliations. 